\title{
EFFECT OF DIFFERENT DENTIN TREATMENT PROTOCOLS ON SURFACE ROUGHNESS AND COMPOSITE BONDING
}

\author{
Raghda A. Okda ${ }^{1 *} B D S$, Ahmed S. El kadi ${ }^{2} P h D$, Fayza H. AlAbbassy ${ }^{3} P h D$
}

\begin{abstract}
INTRODUCTION: With advances in technology, other options besides the traditional cavity preparation with diamond and carbide burs have emerged; among them are laser and sono-abrasive systems.

OBJECTIVES: The aim of this study was to compare in vitro the effect of (Er:YAG) laser with different radiation distances, sono-abrasion and rotary cutting on the surface roughness of dentin and the shear bond strength of resin composite to dentin using self-etching adhesive system.

MATERIALS AND METHODS: 50 extracted human molars were randomly divided into 5 groups (n=10) received the following treatments. Group 1: carbide bur, Group 2: diamond bur, Group 3: sono-abrasion, Group 4: contact Er:YAG laser, Group 5: non-contact Er:YAG laser. Average surface roughness $(\mathrm{Ra})$ was determined with a profilometer. Specimens in all groups were treated with self-etching adhesive system and composite build ups were done with Filtek Z-250. Bonding of resin composites to the dentine specimens was tested in shear mode. For morphological analysis; two extra teeth from each group were examined using a scanning electron microscope (SEM).

RESULTS: The shear bond strength of composite to the laser irradiated dentine (contact and non-contact) ranged from $6.64 \pm 5.24 \mathrm{MPa}$ and $6.29 \pm 2.08 \mathrm{MPa}$ respectively, and were significantly lower than the bond strength seen in other groups. However, the surface roughness of the laser irradiated dentine was significantly higher than that of the sono-abraded dentine and bur-cut dentine. SEM revealed that, the dentine surfaces irradiated by laser showed a scaly and rugged appearance and open dentinal tubules without smear layer production.

CONCLUSIONS: It was concluded that Er:YAG laser treatment reduced shear bond strength of resin composite to dentin in comparison with conventional treatment with high speed rotary and treatment with sono-abrasion. Different Er:YAG laser distance irradiations did not
\end{abstract} influence the shear bond strength of composite to dentin.

KEYWORDS: Er:YAG laser, sono-abrasion, dentin, composite resin, bond strength

1- Resident at Conservative Dentistry Department, Faculty of Dentistry, Alexandria University, Alexandria, Egypt.

2- Professor of Conservative Dentistry, Faculty of Dentistry, Alexandria University, Alexandria, Egypt.

3- Professor of Dental Biomaterials Department, Faculty of Dentistry, Alexandria University, Alexandria, Egypt.

*Corresponding author:

E-mail:dr.ragdaokda@yahoo.com

\section{INTRODUCTION}

For several decades, dentists have been using conventional mechanical cutting and drilling systems to remove diseased dental hard tissues and to prepare cavities for restorations. But the current trend towards minimum-intervention dentistry has introduced alterative techniques for dental cavity preparation in order to replace the invasive approach using high-speed burs (1). These techniques can be classified as mechanical and non-mechanical. The first involves manual and rotary excavation, sono-abrasion and ultrasonic abrasion. The second involves chemomechanical and enzymatic air abrasive methods and lasers. The use of laser irradiation has been widely studied and applied for that purpose, due to its precise and effective ability to eliminate carious tissue while avoiding removal of sound tooth substrate, thus resulting in a more conservative cavity design. And their advantages have also drawn numerous researchers to investigate various applications of lasers in dentistry (2).

Recently, new laser systems were introduced into the dentistry. Among the various laser types adopted to dentistry, the erbium: yttrium aluminum garnet (Er:YAG) laser apparently is one of the most recommended types of lasers, because its wavelength $(2.94 \mu \mathrm{m})$ coincides with the main absorption peek of water $(\sim 3.0 \mu \mathrm{m})$ and is also well absorbed by $\mathrm{OH}$ groups in hydroxyapatite (3) using a pulsed-beam system and fiber delivery. The mechanism of the effect of this laser was generally accepted that water droplets produced violent microexpansion after efficiently absorbing the laser energy which subsequently formed hydrokinetic forces that could quickly ablate the dental hard tissue (4). It has been recommended for minimally invasive purposes, due to its precise ablation of dental structure without side-effects to the pulp and surrounding tissues (5). Despite its efficiency, reported bond strengths of composite resin to tooth substrate prepared by laser are often confusing and contradictory (6-9).

The generic term of sono-abrasion covers the oscillatory diamond abrasive techniques that have been developed in the 1990s specifically for the preparation of small proximal cavities, the main advantage of this technique is the prevention of iatrogenic damage to the adjacent tooth, provided a diamond tip with a smooth nonworking surface is used (10). Other advantages of this preparation method are reduced noise, minimal damage to the gingival tissue, extended bur durability, improved proximal cavity access, and minimal risk to the patient of metal contamination (11).

These innovative technologies used for dental treatment produce dentin surfaces with different characteristics, which may influence the bond strength of adhesive systems, thus, the aim of this study was to investigate the effect of different methods of dentin preparation on dentin bond strength of self-etching adhesive system. The null hypothesis of the present study is that there is no difference in shear bond strength of composite bonded 
to dentin substrate prepared with conventional burs, sonoabrasion, contact and non-contact laser.

\section{MATERIALS AND METHODS}

Table 1 Shows the materials used in this study.

Table (1): Composition of resin materials used in this study.

\begin{tabular}{||l|l||}
\hline \multicolumn{1}{|c|}{ Material } & \multicolumn{1}{|c|}{ Composition } \\
\hline $\begin{array}{l}\text { Adper Scotchbond SE self-etch } \\
\text { adhesive (3M ESPE, St Paul, MN, } \\
\text { USA) }\end{array}$ & $\begin{array}{l}\text { 10-MDP, HEMA, Vitre-bond } \\
\text { copolymer, filler, ethanol, water, } \\
\text { initiators, silane }\end{array}$ \\
\hline \multirow{2}{*}{ Filtek Z250 } & $\begin{array}{l}\text { BIS-GMAM UDMA, BIS-EMA, } \\
\text { PEGDMA, TEGDMA, Zirconium, } \\
\text { Silica }\end{array}$ \\
\hline
\end{tabular}

Abbreviations: Bis-GMA, bisphenol-A diglycidyl ether dimethacrylate; Bis-EMA, ethoxylated bisphenol-Adimethacrylate; TEGDMA, triethyleneglycol dimethacrylate; UDMA, urethane dimethacrylate.

\section{I.Specimen preparation}

A total of 50 non-carious human third molars were used in this study. For disinfection of the extracted teeth, they were subsequently kept in $0.5 \%$ Chloramines-B- hydrate solution for seven days and then stored in distilled water at room temperature. The crown portions were horizontally sectioned at level of CEJ using a diamond disc (Jota AG Rüthi/SG Switzerland) under continuous water cooling, then embedded in self-cure acrylic resin (Acrostone, Egypt), with the buccal surface facing upwards for surface treatment and composite bonding. After polymerization of the embedding resin, buccal surfaces were abraded until a uniform layer of dentin was observed and then sequentially polished in a polishing machine using 400 grit and 600 grit silicon carbide paper under water cooling for 1 minute. Then, the samples were randomly divided into five groups of $(n=10)$ in each according to dentin surface preparation.

\section{a. Grouping and surface treatment}

Group I (carbide bur): The conventional carbide bur (No: H21.010, komet, Lemgo, Germany) was mounted in a dental turbine at high-speed approximately 340,000 rpm with air/water spray cooling. A new bur was used after every five preparations. The preparation was carried out through 10 sweeps of the bur and a constant pressure of hand on the dentin (12). Group II (diamond bur): The conventional diamond tip (No: 838.314.010, komet, Lemgo, Germany) was mounted in a dental turbine at highspeed. The preparation was carried out as mentioned in group I. Group III (Sono-abrasion): Dentin surfaces were prepared with a partially diamond-coated oscillating preparation tip was operated according to the parameters recommended by manufacturer (oscillating at $28 \mathrm{KHz}$ sonic frequency, $8 \mathrm{~W}$ of electric output power, $120 \mathrm{ml} / \mathrm{min}$ rate of water flow) in a sonic device (SONICflex 2000N, Kavo). The pattern of wear was performed in the same manner described above for group I and II, under copious air-water spray. Group IV (Contact Er:YAG laser): The Er:YAG laser (Lightwalker AT, manufactured by Fotona d.d) was used to prepare dentin with emission wavelength of 2.94 micron. The laser system was fitted with a contact handpiece, with no distance from the buccal surface (beam spot size in focus $1 \mathrm{~mm})$. The laser beam was aligned perpendicular to the surface and moved in sweeping fashion by hand during exposure period. Group V (Non-contact Er:YAG laser): Dentin surfaces were irradiated with Er:YAG laser (Lightwalker, manufactured by Fotona), the laser system was fitted with a tip-less (non- contact) hand-piece (4 mm distance from the buccal, spot size $1 \mathrm{~mm}$ ). The distance was standardized using an endodontic -file attached to the tip of the handpiece. Dentin surfaces were irradiated with an Er:YAG laser with the following parameters (1) energy output: $200 \mathrm{~mJ}$; (2) repetition rate: $10 \mathrm{~Hz}$; (3) pulse duration: $450 \mu \mathrm{s}$; (5) water cooling: $5 \mathrm{~mL} / \mathrm{min}$.

\section{b.Surface roughness measurements}

Dentin surface roughness of each specimen was measured using a surface profilometer (MarSurf PS1; Mahr GmbH, Gottingen, Germany). Each traverse of the profilometer stylus was made from the occlusal toward the gingival approximately parallel to the long axis of the tooth. For each specimen, the average roughness $(\mathrm{Ra})$ which is the arithmetic average height of roughness irregularities was measured and recorded in microns.

\section{c. Dentin bonding and resin composite restoration}

Once the dentine surfaces were prepared as described above, they were coated with light-cured Adper Scotchbond SE one step self-etch universal adhesive (3M ESPE, St Paul, MN, USA). The adhesive was applied according to the Manufacturer's instructions, rubbed for 20 seconds, dried with oil-free air for 5 seconds and then light-cured for 20 seconds using a LED light curing unit (Woodpecker, Henan, China). The Filtek Z250 resin (3M ESPE) was then bonded to the dentine samples with a Teflon mold, and then lightcured in two layers for 20 sec each to form a resin cylinder $3 \mathrm{~mm}$ in height and $3 \mathrm{~mm}$ in diameter (table 1).

\section{d.Aging procedure}

All the test specimens were thermocycled in a thermocycling machine for 500 cycles in hot and cold water baths at a temperature range between $5{ }^{\circ} \mathrm{C}$ and $55^{\circ} \mathrm{C}$ with a 30 second dwell time and a transfer time of 30 seconds corresponding to 6 months of clinical service prior to shear bond strength testing (13).

\section{e. Shear bond strength test}

After thermocycling all specimens were secured to a metal mold in the lower platform of the universal testing machine (Cometen Industries, USA. Dental Biomaterials Department, Faculty of Dentistry, Alexandria University) equipped with a chisel-shaped rod was used to deliver the shearing stress. The specimens were oriented so that the rod was against and parallel to the resin-dentine bonding site. The bonded resin-dentine specimens sustained continuous loading at $0.5 \mathrm{~mm} / \mathrm{min}$ until fracture.

\section{f. Failure mode investigation}

Failure mode was investigated using operating microscope under $1.8 \times$ magnification and the results were classified as follows: adhesive, cohesive and mixed. If the composite resin restoration had fractured at the adhesive-tooth interface, it was recorded as adhesive failure. If the composite resin restoration had fractured inside the composite resin or dentin, it was recorded as cohesive failure. If a combination of adhesive and cohesive in dentin or in resin had occurred, it was recorded as mixed failure.

\section{II.Scanning electron microscopic (SEM) evaluation}

For illustrative purposes and to compare the surface morphology of the prepared dentin surfaces and irradiated dentin surfaces, two extra specimens from each type of dentin treatment were prepared for observation under SEM. They were dehydrated in an ascending series of ethanol ( $50 \%$ for $2 \mathrm{hr}$, $70 \%$ for $2 \mathrm{hr}, 95 \%$ for $2 \mathrm{hr}, 100 \%$ for $2 \mathrm{hr}$ ) and dried. They were then mounted on aluminum stubs and sputter coated with gold/palladium and then photographed 
at $2000 \times$ magnification. Examination of SEM (JOEL JSM -5300 Scanning Microscope, Japan) operating at $20 \mathrm{kV}$ was performed.

\section{Statistical analysis}

Kruskal Wallis test was used for abnormally distributed quantitative variables, to compare between more than two studied groups and Post Hoc (Dunn's multiple comparison tests) for pairwise comparisons.

Spearman coefficient to correlate between two distributed abnormally quantitative variables.

\section{RESULTS}

\section{Surface roughness measurements}

In table 2, it can be seen that the surface roughness values (Ra) for the laser irradiated dentinal surfaces with different radiation distances (contact and non-contact) ranged from $2.35 \pm 0.16 \mu \mathrm{m}$ and $2.55 \pm 0.08 \mu \mathrm{m}$, respectively, which were significantly higher $(\mathrm{p}<0.05)$ than the surface roughness mean values seen in group I (carbide bur) $0.40 \pm$ $0.04 \mu \mathrm{m}$, group II (diamond bur) $0.61 \pm 0.04 \mu \mathrm{m}$ and group III (sono-abrasion) $0.59 \pm 0.05 \mu \mathrm{m}$. Also noted that the surface roughness mean values $(\mathrm{Ra})$ of the specimens prepared using diamond bur and sono-abrasion (Group II and III) were significantly higher than those prepared using carbide bur (group I) (table 2).

Table (2): Mean surface roughness (Ra) and shear bond strength of dentin subjected to different treatments.

\begin{tabular}{|c|c|c|c|}
\hline Group & Treatment & Ra $(\boldsymbol{\mu m})$ & $\begin{array}{c}\text { Shear strength } \\
(\mathbf{M P a})\end{array}$ \\
\hline I & Carbide bur & $0.40^{\mathrm{c}} \pm 0.04$ & $10.0^{\mathrm{ab}} \pm 2.63$ \\
\hline II & Diamond bur & $0.61^{\mathrm{b}} \pm 0.04$ & $11.58^{\mathrm{a}} \pm 7.05$ \\
\hline III & Sono-abrasion & $0.59^{\mathrm{b}} \pm 0.05$ & $10.19^{\mathrm{a}} \pm 4.0$ \\
\hline IV & Contact Er:YAG lase & $2.35^{\mathrm{a}} \pm 0.16$ & $6.64^{\mathrm{b}} \pm 5.24$ \\
\hline V & $\begin{array}{c}\text { Non-contact Er:YAG } \\
\text { laser }\end{array}$ & $2.55^{\mathrm{a}} \pm 0.08$ & $6.29^{\mathrm{b}} \pm 2.08$ \\
\hline
\end{tabular}

Values are means \pm standard deviation (SD). Means values with Common letters are not significant $(p>0.05)$ (i.e. Means with Different letters are significant) according to Kruska Wallis Test and Post-Hoc multiple comparisons.

\section{Shear bond strength test}

Mean shear bond strength values for the different treatment groups are presented along with their standard deviation in Table 2. The highest mean bond strength was recorded in group II (diamond bur) (11.58 $\pm 7.05 \mathrm{MPa})$, followed by group III (Sono-abrasion) $(10.19 \pm 4.06 \mathrm{MPa})$, followed by group I (carbide bur) $(10.0 \pm 2.63 \mathrm{MPa})$, followed by group $\mathrm{V}$ (Non-contact Er:YAG) $(6.29 \pm 2.08 \mathrm{MPa})$, and by group IV (contact Er:YAG) $(6.64 \pm 5.24 \mathrm{MPa})$. The bond strength values obtained using diamond bur (Group II) were significantly higher than those obtained with Er:YAG laser with different radiation distances (contact and non-contact) (Group IV and V), however were not statistically different from the group that used sono-abrasion (group III). Finally diamond bur, sono-abrasion and Er:YAG laser groups were similar to carbide bur group (group I) (table 2).

\section{Correlation between surface roughness and shear bond strength}

The correlation between surface roughness measurements and shear bond strength testing are shown in (table 3). According to Spearman coefficient test to correlate between two distributed abnormally quantitative variables, there was no statistically significant correlation between the surface average roughness $(\mu \mathrm{m})$ and the shear bond strength values $(\mathrm{MPa})$ in all groups $(\mathrm{P}>0.05)$.

Table (3): Correlation between surface roughness measurements and shear bond strength testing (SBS) $[\mathrm{N}]$ in each group.

\begin{tabular}{|l|c|c|c|}
\hline \multirow{2}{*}{$\begin{array}{l}\text { Shear bond strength } \\
\text { testing (SBS)[N] }\end{array}$} & \multirow{N}{*}{} & \multicolumn{2}{|c|}{$\begin{array}{c}\text { Surface roughness } \\
\text { measurements }\end{array}$} \\
\cline { 3 - 4 } & & $\mathbf{r}_{\mathbf{s}}$ & $\mathbf{p}$ \\
\hline Group I & $\mathbf{1 0}$ & 0.141 & 0.697 \\
\hline Group II & $\mathbf{1 0}$ & -0.225 & 0.532 \\
\hline Group III & $\mathbf{1 0}$ & -0.164 & 0.650 \\
\hline Group IV & $\mathbf{1 0}$ & 0.134 & 0.713 \\
\hline Group V & $\mathbf{1 0}$ & -0.614 & 0.059 \\
\hline
\end{tabular}

rs: Spearman coefficient

\section{Failure mode}

Failure mode was presented in table 4. Adhesive failure between resin and dentin was predominantly observed in groups irradiated with Er:YAG laser, while mixed failure dominated in groups prepared with carbide bur, diamond bur and sono-abrasion (table 4).

Table (4): Results of failure modes of specimens as a percentage of the total bonding area $(n=10)$.

\begin{tabular}{|l|c|c|c||}
\hline \multicolumn{1}{|c|}{ Groups } & $\begin{array}{c}\text { Adhesive } \\
\text { failure }\end{array}$ & $\begin{array}{c}\text { Cohesive } \\
\text { failure }\end{array}$ & $\begin{array}{c}\text { Mixed } \\
\text { failure }\end{array}$ \\
\hline Group I (Carbide bur) & $4(40 \%)$ & 0 & $6(60 \%)$ \\
\hline Group II (Diamond bur) & $2(20 \%)$ & 0 & $8(80 \%)$ \\
\hline $\begin{array}{l}\text { Group III (Sono- } \\
\text { abrasion) }\end{array}$ & $3(30 \%)$ & $1(10 \%)$ & $6(60 \%)$ \\
\hline $\begin{array}{l}\text { Group IV (Contact } \\
\text { Er:YAG laser) }\end{array}$ & $6(60 \%)$ & 0 & $4(40 \%)$ \\
\hline $\begin{array}{l}\text { Group V (Non-contact } \\
\text { Er:YAG) }\end{array}$ & $7(70 \%)$ & 0 & $3(30 \%)$ \\
\hline
\end{tabular}

\section{SEM evaluation}

The laser-irradiated dentin samples revealed rough surfaces with opened dentinal tubules, an absence of a smear layer, and more prominent peritubular dentin than intertubular dentin. On the other hand, the micrograph of dentin surfaces prepared with carbide bur, diamond bur and sono-abrasion showed the typical appearance of a homogeneous smear layer created with the bur that was partially or totally occluded the dentinal tubules (figures 1, 2).

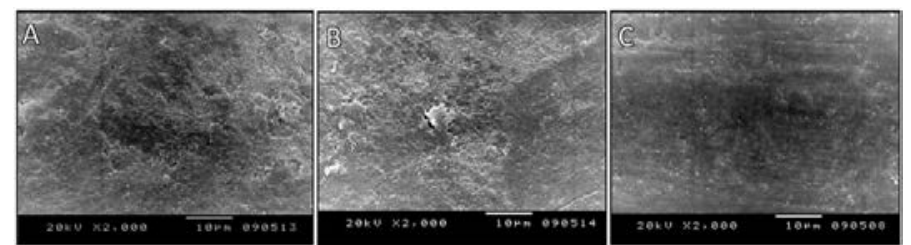

Figure (1): SEM of the prepared dentin surfaces, a) carbide bur, b) diamond bur, c) Sono-abrasion (2000×); a smooth and uniform smear layer is evident with dentinal tubules totally or partially obliterated. 


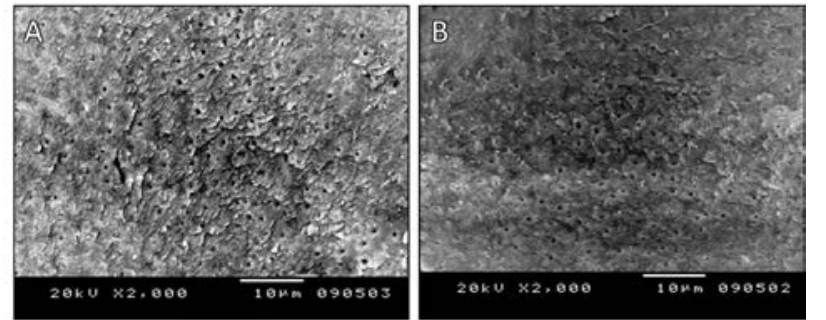

Figure (2): SEM of the irradiated dentin surfaces, a) Contact Er:YAG laser, b) Non- contact Er:YAG laser; opened dentinal tubules, an absence of smear layer, and more prominent peritubular dentin than intertubular dentin can be seen.

\section{DISCUSSION}

The surface created at the end of cavity preparation plays a significant role in the bonding of adhesive restorative materials to tooth structure. Drilling with a bur is the most common way of cavity preparation which often leads to more extensive cavities. This drawback of rotary instruments, along with the current trend toward "minimal invasiveness" has led to introduction of alternative methods for cavity preparation such as laser irradiation and sonoabrasion.

The Er:YAG laser is one of the most recommended types of lasers to be used on dental hard tissues, because its wavelength $(2.94 \mu \mathrm{m})$ coincides with the main absorption peak of water, resulting in good absorption in all biologic tissues, including enamel and dentin. The impact of light energy causes an instant vaporization of the water with massive volumetric expansion. This expansion causes surrounding material to ablate. The chemical composition and structure of dental substrate irradiated with Er:YAG laser differ from that prepared by rotary cutting instruments, the presence of these alterations can somehow affect the bonding of composite resins (14).

Sono-abrasion techniques have displayed recognized good performance and have applications in all aspects of restorative dentistry specifically for the preparation of small proximal cavities for adhesive restoration. The main advantage of this technique is the prevention of iatrogenic damage to the adjacent tooth, provided a diamond tip with a smooth non-working surface is used. The surface created at the end of cavity preparation will play a significant role in the bonding of the adhesive restorative materials to tooth structure (15). There is no reported research comparing the effects of conventional rotary instruments, Er:YAG laser irradiation and sono-abrasion on surface of dental substrate, and, consequently, the bond strength of surfaces prepared by these new technologies and restored with self-etching systems.

Our study was conducted in vitro to assess the effect of different preparation methods, conventional rotary instruments (carbide and diamond burs), sono-abrasion, contact and non-contact Er:YAG laser on surface roughness of human dentin and the shear bond strength between nanohybrid composite resin and prepared dentin surfaces using self-etching adhesive system, as well as evaluated the dentin surface topography by a scanning electron microscope.

The results of the present study support the rejection of the null hypothesis that the dentin surface preparation using different preparation methods exerts no influence on surface roughness of dentin and on resin bond strength, since the lowest bond strength were seen in laser prepared groups as compared with groups prepared with conventional rotary instruments and sono-abrasion with the differences between them being statistically significant $(\mathrm{p}<0.05)$.

Despite the fact that the surface roughness of laserirradiated dentine was significantly $(\mathrm{p}<0.05)$ higher than other groups, therefore in the present study there was no statistically significant correlation between the surface average roughness $(\mathrm{Ra})$ and the shear bond strength values $(\mathrm{MPa})$ in all groups $(\mathrm{P}>0.05)$.

The increase of temperature produced by laser/dentin interaction might be one cause for the decrease mechanical properties (16). It results in a modified surface, in which the collagen network completely melted and vaporized. Thus the denatured collagen fibrils are fused together and poorly attached to the underlying dentin, preventing proper dentin hybridization. These altered microstructures would hamper the infiltration of primer and the hybrid layer would become more susceptible to hydrolysis (17). Also, it has been demonstrated that the denatured organic matrix blocks the diffusion pathways of adhesive in dentin. The diffusion pathway blockage affects the porosity of the structures and consequently impairs penetration of the adhesive components (18).

Moreover, after laser irradiation, the dental surfaces are chemically modified. Irradiation with erbium lasers promotes loss of carbonate, formation of new hydroxyapatite- like crystals, and consequently more acidresistant surfaces (19). Asli et al. (20), found that during laser irradiation, the evaporation of organic components may well lead to an increase in $\mathrm{Ca}, \mathrm{P}, \mathrm{Mg}$ contents in the laser-modified dentin, resulting in acquired acid resistance of dentin surface, in turn, affecting the adhesion of dental materials to dental hard tissue. Hossain et al. (21), also asserted that acid resistance may be promoted by Er,Cr: YSGG laser, the same erbium family as Er:YAG laser.

The result of the current study are in agreement with the results obtained by Cardoso et al. (17), who suggested that the irregularities on the lased dentine surface were so prominent that they may reduce the bond strength by preventing uniform stress distribution at the adhesive dentine interface. Moreover, because of these irregularities, the thickness of the adhesive layer was not uniform on the dentine surface, thus resulting in diminished bonding effectiveness.

The strength of the bond between the composite resin and the dentine is also affected by hybridization and resin tag formation. Aranha et al. (22), found gap formation between the dentine and the resin in laser-prepared cavities, suggesting alterations in collagen. The alterations in collagen seen with the Er, Cr: YSGG irradiated dentine resulted in reduced bond strengths. Also Van Meerbek et al (15) reported that bonding to Er:YAG irradiated dentin surfaces resulted in significantly lower bonding effectiveness when compared to SiC paper, diamond bur or sono-abrasion prepared surfaces. They attributed this result to the subsurface damage caused by Er:YAG irradiation that also compromised the hybridization effectiveness.

Data obtained from this study is against the results obtained by Visuri et al. (7) as they found that the recorded value of mean shear bond strength of laser irradiated dentin has resulted in much higher value than the cavities prepared by bur. The difference seen between laser treated and handpiece treated samples was likely due to the microscopic differences in the surfaces, particularly the presence of open 
dentin tubules. This difference could be attributed to the difference in the nature and the parameters of laser used and thus the effect on the tooth surface also to the type of the composite that may react differently with the prepared surfaces and yield different results.

In the present study the types of failure observed, by visual inspection supports the result of the shear bond strength test. Adhesive failures between resin and dentin dominated in the laser-irradiated groups.

This type of adhesive failure has also been observed in study by Daneshkazemi AR et al (23) in all tested laser irradiated specimens bonded to silorane- based composite, also are consistent with studies by Souza-Zaroni WC et al (24), while mixed failures dominated in other groups. This result was in agreement with Koumpia EK (25). In the present study, the diamond-bur prepared dentin showed areas of tubules occluded by the presence of the smear layer and smear plugs, as observed with SEM (Fig. 3a,3b), the sono-abrasive diamond tip was not able to completely remove the smear plugs, as demonstrated by the partially opened tubules (Fig. 3c). Laser prepared dentin surfaces revealed opened dentinal tubules, absence of a smear layer and more prominent peritubular dentin than intertubular dentin. Since intertubular dentin contains more water and has a lower mineral content than does peritubular dentin, it is selectively more ablated than the peritubular dentin, leaving protruding dentinal tubules with a cuff like appearance and resulting in more irregular dentin surface (Fig. 2a, 4b). The topographical features are very much similar to the one observed by Verma $M$ et al (26), Chowdhury SR et al (27) and De Oliveira et al (28).

\section{CONCLUSION}

Within the limitation of this study, it may be concluded that:

1. The use of the laser may have a negative effect on bond strength in comparison to traditional bur preparation and sono-abrasion.

2. Using the surface preparation methods demonstrated in this study, surface roughness had no effect on the shear bond strength of self-etching adhesives.

3. There was a negative correlation between surface roughness and SBS.

4. The dentin surfaces irradiated by the Er:YAG laser had rough and scaly surfaces that were devoid of any smear layer compared with conventional mechanical tooth preparation.

\section{CONFLICT OF INTEREST}

No potential conflict of interest relevant to this article was reported.

\section{REFERENCES}

1-Tyas MJ, Anusavice KJ, Frencken JE. Minimal intervention dentistry-a review. Int Dent J. 2000;50:1-12.

2-Stern RH, Sognnaes RF. Laser beam effect on dental hard tissues. J Dent Res. 1964;43:873.

3-Keller U, Hibst R. Experimental studies of the application of the Er:YAG laser on dentalhard substances. II. Light microscopic and SEM investigations. Lasers Surg Med. 1989; 9:345-51.

4-Lussi A, Megert B, Longbottom C, Reich E, Fransescut P. Clinical performance of a laser fluorescence device for detection of occlusal caries lesions. Eur J Oral Sci. 2001;109:14-9.

5-Ying D, Chuah GK, Hsu CY. Effect of Er:YAG laser and organic matrix on porosity changes in human enamel. $\mathrm{J}$ Dent. 2004;32:41-6.

6-Carrieri TC, Freitas PM, Navarro RS, Eduardo CP, Mori M. Adhesion of composite luting cement to Er:YAG lasertreated dentin. Lasers Med Sci. 2007;22:165-70.

7-Visuri SR, Gilbert JL, Wright DD, Wigdor HA, Walsh JT Jr. Shear strength of composite bonded to Er:YAG laserprepared dentin. J Dent Res. 1996;75:599-605.

8-Botta SB, da Ana PA, Zezell DM, Pawers JM, Matos AB. Adhesion after erbium, chromium: yttriumscandiumgallium-garnet laser application at three different irradiation conditions. Lasers Med Sci. 2009;24:67-73.

9-Armengol V, Jean A, Weiss P, Hamel H. Comparative in vitro study of the bond strength of composite to enamel and dentin obtained with laser irradiation or acid- etch. Lasers Med Sci. 1999;14:207-15.

10-Hugo B, Stassinakis A. Preparation and restoration of small interproximal carious lesions with sonic instruments. Pract Periodont Aesthet Dent. 1998;10:353-9.

11-Carvalho CA, Fagundes TC, Barata TJ, Trava-Airoldi VJ, Navarro MF. The use of CVD diamond burs for ultraconservative cavity preparations: A report of two cases. J Esthet Restor Dent. 2007;19:19-28.

12-Da Silva MA, Di Nicolo R, Barcellos DC, Batista GR, Pucci CR, Rocha Gomes Torres C, Borges AB. Influence of CVD diamond tips and Er:YAG laser irradiation on bonding of different adhesive systems to dentin. J Contemp Dent Pract. 2013;14:14-20.

13-Dunn WJ, Davis JT, Bush AC. Shear bond strength and SEM evaluation of composite bonded to Er:YAG laserprepared dentin and enamel. Dent Mater. 2005;21:616-24.

14-Eguro T, Maeda $\mathrm{T}$, Tanabe $\mathrm{M}$, Otsuki M, Tanaka $\mathrm{H}$. Adhesion of composite resins to enamel irradiated by the Er:YAG laser: Application of the ultrasonic scaler on irradiated surface. Lasers Surg Med. 2001;28:365-70.

15-Van Meerbeek B, De Munck J, Mattar D, Van Landuyt K, Lambrechts PB. Microtensile bond strengths of an etch \& rinse and self-etch adhesive to enamel and dentins as a function of surface treatment. Oper Dent. 2003;28:647-60.

16-Kim YI, Hwang IN, Oh WM. Thermal change of the dentin by use of pulsed Nd: YAG laser. J Korean Acad Conserv Dent. 1996;21:218-26.

17-Cardoso MV, De Munck J, Coutinho E, Ermis RB, Van Landuyt K, de Carvalho RC, et al. Influence of Er,Cr:YSGG laser treatment on the microtensile bond strength of adhesives to dentin. J Adhes Dent. 2008;10:25-33.

18-Tay FR, Carvalho RM, Yiu CK, King NM, Zhang Y, Agee $\mathrm{K}$, et al. Mechanical disruption of dentin collagen fibrils during resin-dentin testing. J Adhes Dent. 2000;2:175-92.

19-Apel C, Meister J, Gotz H, Duschner H, Gutknecht N. Structural changes in human dental enamel after subablative erbium laser irradiation and its potential use for caries prevention. Caries Res. 2005;39:65-70.

20-Secilmis A, Altintas S, Usumez A, Berk G. Evaluation of mineral content of dentin prepared by erbium,chromium: yttrium scandium gallium garnet laser. Lasers Med Sci. 2008;23:421-5.

21-Hossain M, Kimura Y, Nakamura Y, Yamada Y, Kinoshita JI, Matsumoto K. A study on acquired acid resistance of enamel and dentin irradiated by Er,Cr:YSGG Laser. J Clin Laser Med Surg. 2001;19:159-63. 
22-Aranha ACC, Eduardo CP, Gutknecht N, Marques MM, Ramalho KM, Apel C.. Analysis of the interfacial micromorphology of adhesive systems in cavities prepared with Er,Cr:YSGG, Er:YAG laser and bur. Microsc Res Tech. 2007;70:745-51.

23-Daneshkazemi A, Modabber M, Davari A, Ravaii S. Comparative Study on Microtensile Bond Strength of Silorane-based Composite in Dentin Cavity Prepared with Erbium: Yttrium Aluminum Garnet Laser versus Bur-cut. J Int Oral Health. 2016;8:843-9.

24-Souza-Zaroni WC, Chinelatti MA, Delfino CS, Pécora JD, Palma-Dibb RG, Corona SA. Adhesion of a self-etching system to dental substrate prepared by Er: YAG laser or air abrasion. J Biomed Mater Res B Appl Biomater. 2008;86:321-9.

25-Koliniotou-Koumpia E, Kouros P, Dionysopoulos D, Zafiriadis L. Bonding strength of silorane-based composite to Er-YAG laser prepared dentin. Lasers Med Sci. 2015;30:509-16.
26-Verma M, Kumari P, Gupta R, Gill S, Gupta A. Comparative evaluation of surface topography of tooth prepared using erbium, chromium: Yttrium, scandium, gallium, garnet laser and bur and its clinical implications. J Indian Prosthodont Soc. 2015;15:23-8.

27-Chowdhury SR, Marques MM, Franzen R. Pedroni ANF, Trevelin LT, Abe GL, et al. Comparative ultrastructural analysis of Er:YAG laser scanner and conventional method for tooth cavity preparation. Laser Dent Sci. 2017;1:23-31.

28-De Oliveira MT, de Freitas PM, Carlos de Paula Eduardo, Ambrosano GMB, Giannini M. Influence of diamond sonoabrasion, air-abrasion and Er:YAG laser irradiation on bonding of different adhesive systems to dentin. Eur J Dent. 2007;1:158-66.

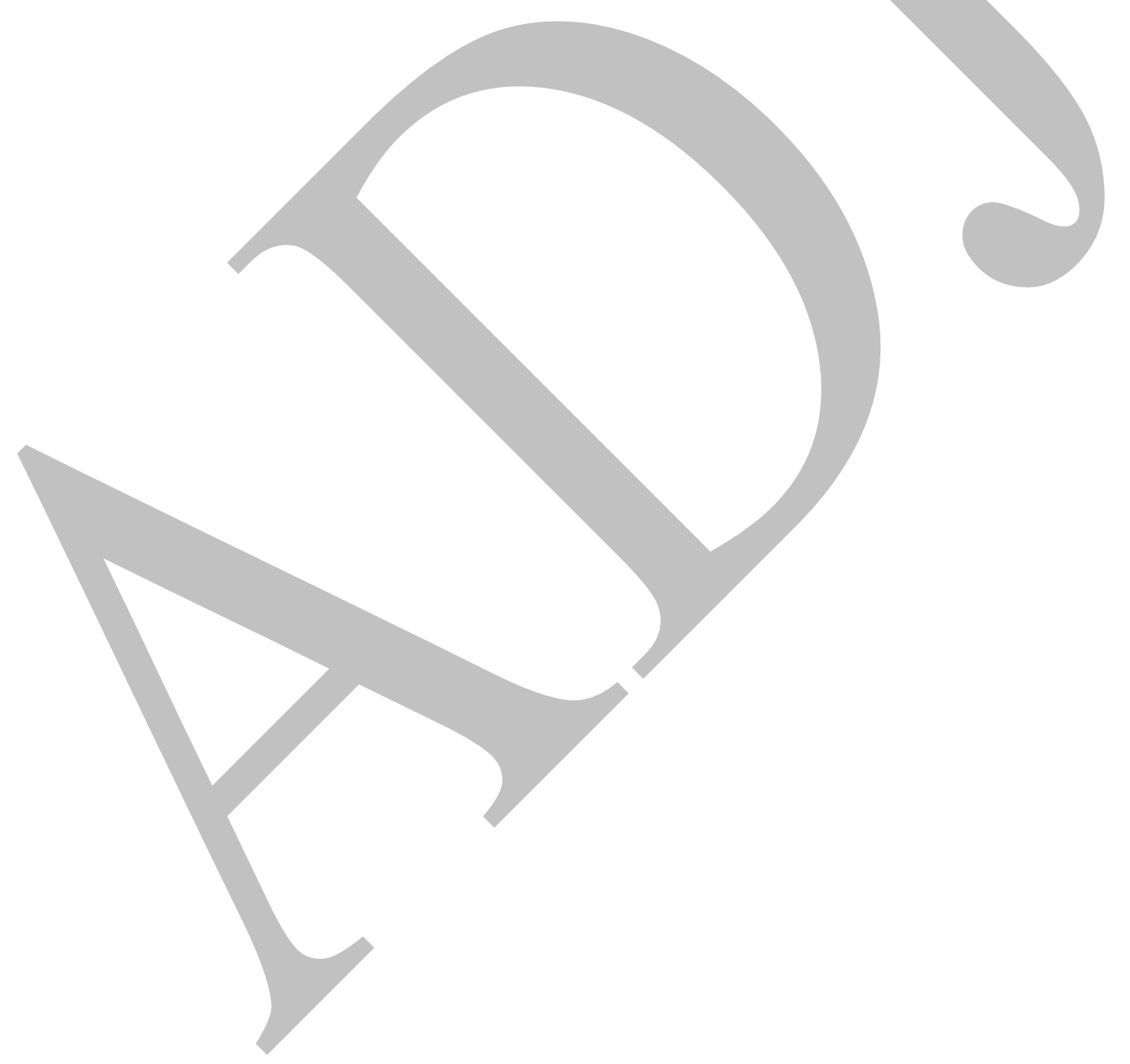

